\title{
Biomechanical Comparison of Same Size Transfacet Screws Versus Pedicle Screws across the L5-S1 Native Disc
}

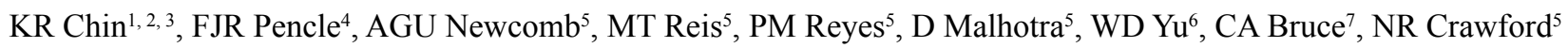

\begin{abstract}
Objective: There is resurgence in facet screw use; however, there is a paucity of data comparing the stability of transfacet pedicle screws (TFPS) to standard pedicle screw-rod constructs at L5-S1. The authors aim to compare the stabilizing potential of TFPS compared to pedicle screws of the same length and diameter at L5-S1 with an intact native disc.

Methods: Flexibility of human cadaveric lumbar spine segments was biomechanically tested in vitro to provide a comparison of two types of posterior stabilization across L5-S1. Fourteen cadaveric spine specimens (T12-S1) were tested in intact condition, then after, surgical procedures were performed at L5-S1 using $5.0 \times 40 \mathrm{~mm}$ transfacet pedicle screws (Group \#1) and same sized pedicle screw-rod construct (Group \#2). Specimens were studied using standard non-destructive pure moment flexibility tests.

Results: Transfacet pedicle screws (TFPS) allowed less motion in all loading modes than bilateral pedicle screw-rod (BPSR) construct, with a significantly smaller range of motion allowed during extension and axial rotation $(\mathrm{p}<0.05)$. Transfacet pedicle screws allow less lateral bending than BPSR compared to the intact specimen, although the magnitude of the difference was less than during flexion or extension.

Conclusion: Bilateral transfacet screws provided better immediate postoperative stability in vitro in intact posterior element facets without osteophytes than equivalent-sized unilateral or bilateral standard pedicle screw at L5-S1. These are limited to a biomechanical application as larger sized pedicle screws are used in the clinical setting. Further biomechanical and clinically relevant studies are warranted to verify these points.
\end{abstract}

Keywords: Diameter screws, equivalent length, L5-S1 intact native disc, pedicle screw-rods Biomechanics, posterior fixation, transfacet pedicle screws

\section{Comparación biomecánica de tornillos transfacetarios del mismo tamaño frente a tornillos pediculares a través del disco nativo L5-S1}

KR Chin ${ }^{1,2,3}$, FJR Pencle ${ }^{4}$, AGU Newcomb ${ }^{5}$, MT Reis ${ }^{5}$, PM Reyes $^{5}$, D Malhotra ${ }^{5}$, WD Yu ${ }^{6}$, CA Bruce ${ }^{7}$, NR Crawford

\begin{abstract}
RESUMEN
Objetivo: Hay ahora un resurgimiento del uso del tornillo facetario. Sin embargo, hay escasez de datos que comparen la estabilidad de los tornillos pediculares transfacetarios (TPTF) con las construcciones de tornillo de barra pedicular estándar en L5-S1. Los autores tienen por objeto comparar el potencial estabilizador de los tornillos TPTF en comparación con los tornillos pediculares
\end{abstract}

From: ${ }^{1}$ Charles E. Schmidt College of Medicine at Florida Atlantic University, USA, ${ }^{2}$ Herbert Wertheim College of Medicine at Florida International University, USA, ${ }^{3}$ Less Exposure Surgery Specialists Institute (LESS Institute), USA, ${ }^{4}$ Less Exposure Surgery (LES) Society, USA, ${ }^{5}$ Barrow Neurological Institute, St Joseph's Hospital and Medical Center, USA, ${ }^{6}$ Department of Orthopaedic Surgery, George Washington University, USA and ${ }^{7}$ Department of
Surgery, Radiology, Anaesthesia and Intensive Care, The University of the West Indies, Mona, Jamaica W.I.

Correspondence: Dr K Chin, Less Exposure Surgery Specialists Institute (LESS Institute), $1100 \mathrm{~W}$. Oakland Park Blvd. Suite \#3, Fort Lauderdale, FL, 33311, USA. Email: kingsleychin@thelessinstitute. com 
de la misma longitud y diámetro en L5-S1 con un disco nativo intacto.

Métodos: La flexibilidad de los segmentos de la columna lumbar cadavéricos humanos fue biomecánicamente sometida a prueba in vitro para proporcionar una comparación de los dos tipos de estabilización posterior a través de L5-S1. Catorce muestras cadavéricas de la espina dorsal (T12-S1) fueron probadas en condiciones intactas, tras lo cual se realizaron procedimientos quirúrgicos en L5-S1 usando tornillos transfacéticos pediculares de $5.0 \times 40 \mathrm{~mm}$ (Grupo \#1) y construcción tornillo de barra pedicular del mismo tamaño (Grupo \#2). Los especímenes fueron estudiados mediante pruebas estándar de flexibilidad de puro momento no destructivas.

Resultados: Los tornillos pediculares transfacetarios (TPTF) permiten menos movimiento en todos los modos de carga que la construcción de tornillo de barra pedicular bilateral (TBPB), que permite un rango de movimiento significativamente menor durante la extensión y rotación axial $(\mathrm{p}<$ 0.05). Los tornillos pediculares transfacetarios permiten menos flexión lateral que la construcción de TBPB, en comparación con la muestra intacta, aunque la magnitud de la diferencia fue menos que durante la flexión o extensión.

Conclusión: Los tornillos transfacetarios bilaterales proporcionaron mejor estabilidad postoperatoria inmediata in vitro en las facetas intactas de los elementos posteriores, sin osteofitos, que los tornillos pediculares estándar bilaterales o los unilaterales de tamaño equivalente, en L5-S1. Éstos se limitan a una aplicación biomecánica ya que los tornillos pediculares de mayor tamaño se usan en el contexto clínico. Se precisa realizar otros estudios biomecánicos y clínicamente relevantes a fin de verificar estas cuestiones.

Palabras claves: Tornillos de diámetro, longitud equivalente, disco nativo intacto de L5-S1, barras de tornillo pediculares, biomecánica, fijación posterior, tornillos pediculares transfacéticos

West Indian Med J 2017; 66 (3): 417

\section{INTRODUCTION}

The pedicles, facets, laminae, and spinous processes are among the anatomical structures that have been used to provide posterior stability in an attempt to increase fusion rates and decrease the need for external immobilization postoperatively (1-6).

The first documented method of lumbar screw fixation used a transfacet technique, conceptualized by King in 1948 (7). With the passage of time, the pedicle screw and rod (PSR) construct became the dominant method of posterior fixation in spine fusion, as this instrumentation was thought to have improved biomechanical stability since screws cross all three columns of the spine (8).

The pendulum seems to be swaying back toward facet screw fixation with growing interest in minimally invasive and less exposure surgery techniques for the advantages of preserving the anatomy such as the adjacent facets and to decrease tissue disruption for lumbar surgeries. Some biomechanical studies of facet screw fixation have demonstrated comparable stability to pedicle screws $(9,10)$.

The transfacet pedicle screw (TFPS) technique developed in 1959 then standardized by Boucher, allowed the use of longer screws for three-column fixation and thus, had the potential to add greater stability to facet screw fixation and may be more stable than traditional PSR fixation (11). Panjabi et al demonstrated stability in axial rotation, however, relatively low stability in other directions of testing between five pedicle fixation systems (12). Other studies by Kretzer et al found no statistically significant differences between two different types of bilateral facet screws, and bilateral pedicle screws at L2-L3 and L4-L5 (13); however, only immediate stability range of motion (ROM) without further investigation of the long-term fatigue behaviour.

Chin et al demonstrated that TFPS provide equivalent stability to PSR at L1-L2 and L2-L3, however, with a Sagittal Lumbar Interbody Fixation Technology (SpineFrontier, MA), PSR demonstrated less susceptibility to loosening (14). Although surgeons consider the middle-to-lower lumbar spine to be the most suitable region when applying TFPS fixation, the lumbosacral junction (L5-S1) is not as frequently considered suitable for this procedure because of the high magnitude of stresses at this level $(15,16)$. However, the very flat and large facet joints and wide pedicles at L5-S1 provide an easily accessible surgical target, and additional study of this level is warranted. The objective of this study was to compare the stabilizing potential at L5-S1 using TFPS to equivalent-sized standard pedicle screw-rods (PSR), both with an intact native disc. We have used the same size PSR screws as the TFPS employed in this study to offer empiric biomechanical data comparing these two constructs, and not as an example of what should be used clinically.

\section{SUBJECTS AND METHODS}

Specimen preparation

Fourteen fresh human cadaveric lumbar spine segments from T12-S1 were used. Mean age \pm standard deviation was $53.1 \pm$ 11.0 years; there were four men and ten women. Dual energy X-ray absorptiometry (DEXA) scans were performed on the L4 vertebra of each specimen to assess bone mineral density 
Table 1. Demographics, bone mineral density (BMD) and intact mobility of all specimens, with mean values ( \pm one standard deviation) for all and both Groups (FF and PS). Also shown are $p$-values (based on non-paired Student $t$-tests) for comparisons between Groups (FF vs PS).

\begin{tabular}{|c|c|c|c|c|c|c|c|}
\hline Number & $\underset{*}{\text { Group }}$ & Gender & $\begin{array}{l}\text { Age } \\
\text { (years) }\end{array}$ & $\begin{array}{c}\text { DEXA } \\
\left(\text { BMD g/cm }{ }^{2}\right)\end{array}$ & $\begin{array}{l}\text { Intact L5- } \\
\text { S1 ROM } \\
\text { FL-EX } \\
\text { (Deg.) }\end{array}$ & $\begin{array}{c}\text { Intact L5- } \\
\text { S1 ROM LB } \\
\text { (avg R\&amp;L) } \\
\text { (Deg.) }\end{array}$ & $\begin{array}{c}\text { Intact L5- } \\
\text { S1 ROM AR } \\
\text { (avg R\&amp;L) } \\
\text { (Deg.) }\end{array}$ \\
\hline 1 & FS & $\mathrm{M}$ & 40 & 0.911 & 15.79 & 4.10 & 2.50 \\
\hline 2 & FS & $\mathrm{F}$ & 39 & 1.067 & 16.12 & 3.31 & 2.88 \\
\hline 3 & FS & $\mathrm{F}$ & 48 & 0.938 & 8.63 & 1.92 & 1.39 \\
\hline 4 & FS & F & 54 & 0.807 & 14.39 & 3.12 & 2.22 \\
\hline 5 & FS & F & 62 & 0.498 & 16.62 & 3.59 & 1.34 \\
\hline 6 & FS & M & 29 & 0.847 & 11.72 & 4.51 & 2.89 \\
\hline 7 & FS & M & 55 & 0.744 & 9.07 & 2.16 & 1.30 \\
\hline 8 & PS & $\mathrm{F}$ & 53 & 1.291 & 15.77 & 3.48 & 3.00 \\
\hline 9 & PS & $\mathrm{F}$ & 50 & 0.797 & 11.08 & 2.75 & 2.33 \\
\hline 10 & PS & F & 61 & 0.900 & 10.25 & 2.70 & 1.95 \\
\hline 11 & PS & M & 65 & 0.792 & 8.63 & 1.94 & 0.89 \\
\hline 12 & PS & $\mathrm{F}$ & 64 & 0.873 & 4.52 & 1.16 & 1.20 \\
\hline 13 & PS & F & 65 & 0.724 & 15.87 & 3.98 & 2.74 \\
\hline 14 & PS & $\mathrm{F}$ & 59 & 0.839 & 10.59 & 2.96 & 1.64 \\
\hline \multirow[t]{3}{*}{$\begin{array}{l}\text { Mean } \\
+/ \text {-SD }\end{array}$} & & All: & $53.1( \pm 11.0)$ & $0.859( \pm 0.178)$ & $\begin{array}{l}12.08 \\
( \pm 3.73)\end{array}$ & $\begin{array}{l}2.98 \\
( \pm 0.95)\end{array}$ & $\begin{array}{c}2.01 \\
( \pm 0.72)\end{array}$ \\
\hline & & PS: & $59.6( \pm 6.0)$ & $0.888( \pm 0.187)$ & $\begin{array}{c}10.96 \\
( \pm 3.98)\end{array}$ & $\begin{array}{c}2.71 \\
( \pm 0.94)\end{array}$ & $\begin{array}{c}1.97 \\
( \pm 0.78)\end{array}$ \\
\hline & & FF: & $46.7( \pm 11.4)$ & $0.830( \pm 0.179)$ & $\begin{array}{c}13.19 \\
( \pm 3.38)\end{array}$ & $\begin{array}{c}3.24 \\
( \pm 0.95)\end{array}$ & $\begin{array}{c}2.07 \\
( \pm 0.72)\end{array}$ \\
\hline$p$-value & & PS vs FF & 0.021 & 0.802 & 0.280 & 0.311 & 0.792 \\
\hline
\end{tabular}

FF: Facet Fuse facet screw; PS: pedicle screw; ROM: range of motion; FL-EX: flexion-extension; LB: lateral bending; AR: axial rotation.

(BMD) and to ensure that specimens were not osteoporotic (Table 1).

Specimens were carefully cleaned of muscular tissue while keeping all ligaments, joint capsules and discs intact. The discs were kept intact to decrease the number of variables focussing on the testing of fixation and were used to help predict their durability in the long run. For testing, the sacrum was reinforced with household wood screws, embedded in a block of polymethylmethacrylate or fast-curing resin (Smooth-Cast 300Q, Smooth-On, Inc, Easton, PA), and attached to the base of the testing apparatus (Fig. 1).

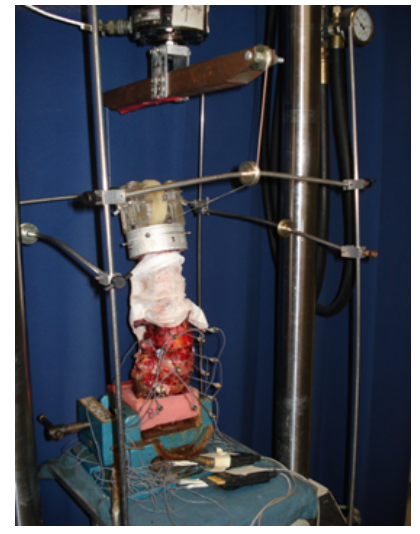

Fig. 1: Photograph of experimental setup.
The T12 vertebra was similarly embedded after inserting reinforcing screws in a cylindrical metal fixture for the application of loads. The spines were tested in the intact condition and then surgical procedures were performed at L5-S1. Specimens were divided into two groups (Table 1): transfacet pedicle screw (TFPS, $n=7$ ) and pedicle screws-rods (PSR, $n=7$ ). In both procedures and groups, screw size was kept constant at $5.0 \times 40 \mathrm{~mm}$ to better analyse the effect of the technique, thus, eliminating screw length and diameter bias. Interconnecting rod diameter in the PSR group was $55 \mathrm{~mm}$. Pedicle screws were top-loaded with variable angle heads and were locked in place using locking caps (Figs. 2A/B/C; PedFuse Return, SpineFrontier Inc, Beverly, MA, USA).

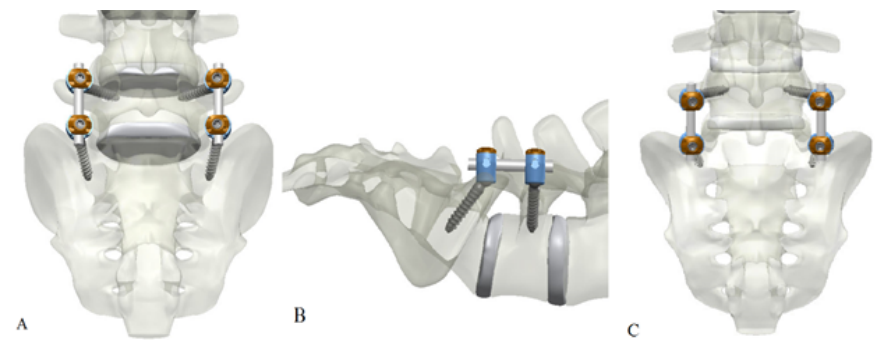

Fig. 2: Computer generated image showing bilateral pedicle screw-rod fixation at L5-S1. (A) anterior-posterior, (B) Lateral and (C) True anterior-posterior.

Used with permission from SpineFrontier Inc., Malden, MA. 
Transfacet pedicle screws had a $12 \mathrm{~mm}$ diameter footprint swivelling head washer with a bevelled face in contact with the bone for even distribution of load around the lamina and articular process (Figs. 3A/B/C; FacetFuse, SpineFrontier Inc).

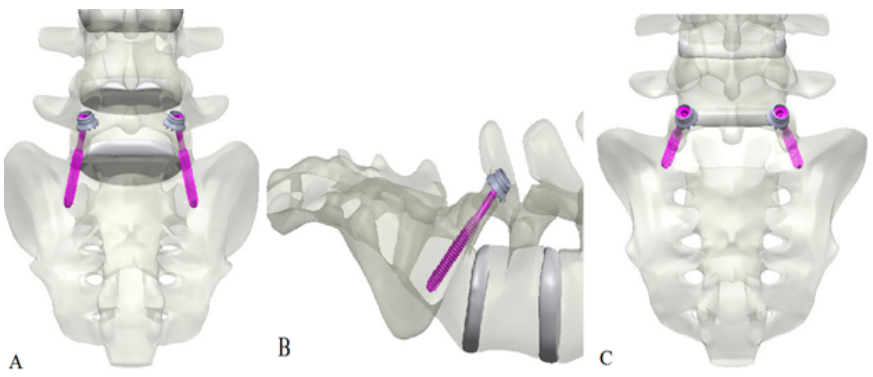

Fig. 3: Computer generated image showing bilateral transfacet pedicle screw L5-S1. (A) anterior-posterior, (B) Lateral and (C) True anterior-posterior. Used with permission from SpineFrontier Inc., Malden, MA.

The descriptions of procedures are as outlined below and are modified to previously described techniques $(11,17)$. The testing protocol in the PSR group was also divided into two steps:1-Bilateral interconnecting rods and 2-Unilateral interconnecting rod. In summary, this protocol generated three groups for analysis and comparisons:1-Bilateral transfacet pedicle screws (1-BPSR), 2-Bilateral pedicle screws-rods (2BPSR) and 3-Unilateral pedicle screws-rod (3-UPSR).

\section{Transfacet pedicle screw technique}

- The starting point is obtained on the anteriorposterior (AP) fluoroscopic projection. The tip of the drill should be placed at a point defined by the intersection of the inferior endplate of the cephalad level and the medial border of the pedicle of the inferior level.

- The coronal trajectory is directed laterally towards the 5 O'clock position for right pedicle and 7 O'clock for left pedicle.

- The sagittal trajectory is obtained on the lateral fluoroscopic projection. The drill path is directed just caudal to the superior pedicle cortex to the anterior inferior corner of the vertebral body.

- The $3.5 \mathrm{~mm}$ drill is advanced using a tap drilling technique to a depth approximately $40 \mathrm{~mm}$ into the vertebral body.

- The 5.0 x $40 \mathrm{~mm}$ cannulated screw is placed (Fig. 4) for standardization of testing after the pilot hole is created with the aid of a probe. A study, by Arman et al showed the antero-medial and anterolateral distance of approximately $50 \mathrm{~mm}$ in the sacrum at S1 level (18) allowing enough distance not to breach the anterior cortex of the sacrum.

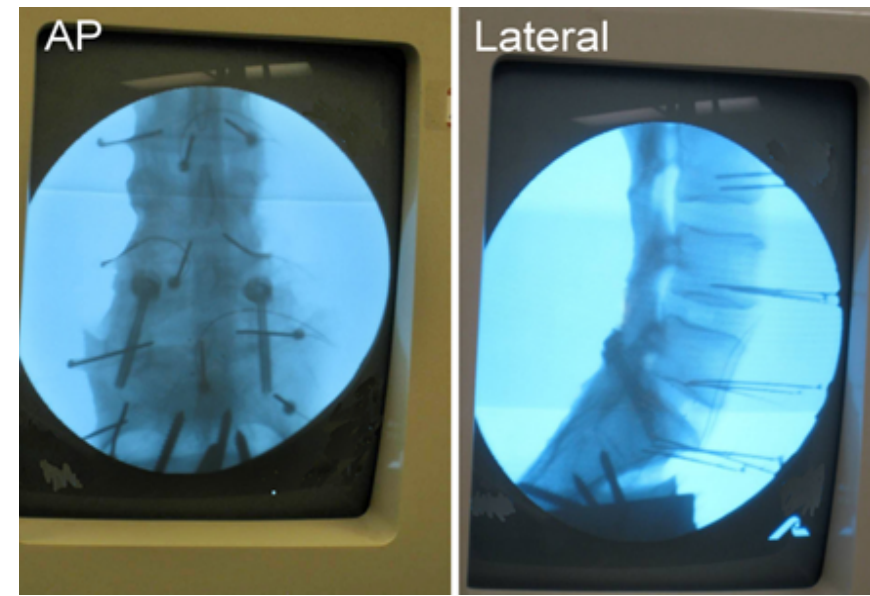

Fig 4: Fluoroscopic image of transfacet pedicle screws setup anterior-posterior and lateral view.

\section{Pedicle screw insertion technique}

- L5 screw was inserted by making a pilot hole in the exterior cortex of the vertebral body at the midpoint of the transverse process just lateral to the border of the superior articular facet.

- A straight pedicle axle was directed along the axis of the pedicle approximately $30^{\circ}$ medial.

- The S1 screw pilot hole was made just lateral to the $\mathrm{S} 1$ facet and directed $35^{\circ}$ medial. A straight pedicle axle was directed along the axis of the pedicle.

- The $4 \mathrm{~mm}$ tap is inserted along the pedicle axis followed by 5.0 x $40 \mathrm{~mm}$ screws.

- $55 \mathrm{~mm}$ rod was inserted into the tulips followed by torqueing of the set screws (caps) to lock construct in place.

\section{Biomechanical Testing}

In all conditions tested, specimens were studied using standard pure moment flexibility tests. Motion data for L5-S1 is presented herewith. For these tests, an apparatus was used in which a system of cables and pulleys imparted nondestructive, non-constraining torques in conjunction with a standard servohydraulic test system (MTS, Minneapolis, $\mathrm{MN}$ ), as we have previously described (19). This type of loading is distributed evenly to each motion segment, regardless of the distance from the point of loading (20). Loads were applied about the appropriate anatomical axes to induce three different types of motion: flexion-extension (FE), right and left lateral bending (LB), and right and left axial rotation (AR). In each loading direction, three preconditioning cycles were applied at $7.5 \mathrm{Nm}$ for 60 seconds each, after which the specimen was allowed to rest at zero load for 60 seconds to allow for creep (21-23). Preconditioning was applied in this way to ensure appropriate settling at the hardware-bone interface and to improve reproducibility of the results. During the data collection cycle, the load was applied quasi-statically in $1.5 \mathrm{Nm}$ increments, with each incremental load held for 45 seconds to a maximum of $7.5 \mathrm{Nm}$. Three parameters were 
generated from the angular quasi-static load-deformation data: angular ROM, lax zone (LZ)-zone of ligamentous laxity, and stiff zone (SZ)-zone of ligamentous stretching. Range of motion was quantified as the angle reached under maximum load $(7.5 \mathrm{Nm})$ in each plane. The angle at which LZ transitions to SZ, which is the "elbow" of the biphasic load-deformation response was found by extrapolating to zero load the quasi-static moment-angle data points at 4.5, 6.0 and 7.5 $\mathrm{Nm}$ using the method of least squares (24).

Three-dimensional specimen motion in response to the applied loads during flexibility tests was determined using the Optotrak 3020 system (Northern Digital, Waterloo, Ontario, Canada). This system measures stereophotogrammetrically the three-dimensional displacement of infrared-emitting markers rigidly attached in a non-collinear arrangement to each vertebra. Custom software converts the marker coordinates to angles about each of the anatomical axes in terms of the motion segment's own coordinate system $(19,25)$. Spinal angles were calculated using a vector technique that provides results specifically suited for describing 3D spinal motion (25).

\section{Data analysis}

From the raw data, three parameters were generated from the quasi-static load-deformation data: angular ROM, LZ and $\mathrm{SZ}$. The LZ and SZ are components of the ROM and represent the low-stiffness and high-stiffness portions of the typically biphasic load-deformation curve, respectively (26). To mitigate the effect of inter-specimen variability, raw values of motion for the instrumented conditions were normalized by dividing the data with the motion incurred in the respective intact conditions. Mean normalized LZ, SZ, and ROM for flexion, extension, lateral bending (average right and left) and axial rotation (average of right and left) were statistically analysed using one-way analysis of variance (ANOVA) followed by Holm-Sidak pairwise tests to assess whether there were differences among means for values obtained in the TFPS and PSR conditions, $p$-values less than 0.05 were considered statistically significant.

In addition to biomechanical assessments, specimens were disarticulated and assessed anatomically after completing tests to determine whether TFPS trajectories crossed facet joint planes and whether screw trajectories remained within the pedicles and if any fractures or osteophytes were present.

\section{RESULTS}

Specimens in both groups has similar BMD (PSR: $0.888 \pm$ $0.187 \mathrm{~g} / \mathrm{cm}^{2}$; TFPS: $0.830 \pm 0.179 \mathrm{~g} / \mathrm{cm}^{2} ; p=0.802$ ), and intact ranges of motion (Table 2, $p>0.13$ ), however, there was a significant difference in mean age (PSR: [59.6 \pm 0.9 years]; TFPS $[46.7 \pm 11.4$ years], $p=0.021$ ). Comparisons between instrumented conditions showed that the mean mobility with TFPS was less than the mean mobility with bilateral PSR in all directions of loading, and significantly so during extension (Table $2, p=0.048$ ). Similarly, TFPS limited ROM was significantly better than unilateral PSR in all directions of loading (Table 2, $p<0.001$ ). The difference between UPSR and BPSR was significant during lateral bending and axial rotation (Table 2, $p<0.02$ ). There were no differences between ipsilateral and contralateral mobility with UPSR during axial rotation (Table 2, $p=0.366$ ) or lateral bending (Table $2, p=$ $0.434)$.

Table 2: $P$-values from one-way analysis of variance (ANOVA)/Holm-Sidak comparing normalized LZ, SZ and ROM

\begin{tabular}{|c|c|c|c|}
\hline Loading mode and comparison & $\mathbf{L Z}$ & $\mathbf{S Z}$ & ROM \\
\hline \multicolumn{4}{|l|}{ Flexion } \\
\hline UPSR vs BPSR & 0.140 & 0.063 & 0.076 \\
\hline UPSR vs TFPS & 0.011 & $<0.001$ & 0.001 \\
\hline TFPS $v s$ BPSR & 0.160 & 0.050 & 0.057 \\
\hline \multicolumn{4}{|l|}{ Extension } \\
\hline UPSR vs BPSR & 0.147 & 0.128 & 0.054 \\
\hline UPSR vs TFPS & 0.011 & 0.006 & $<0.001$ \\
\hline TFPS $v s$ BPSR & 0.160 & 0.108 & 0.048 \\
\hline \multicolumn{4}{|l|}{ Lateral bending } \\
\hline UPSR vs BPSR & 0.002 & 0.029 & 0.003 \\
\hline UPSR $v s$ TFPS & $<0.001$ & $<0.001$ & $<0.001$ \\
\hline TFPS $v s$ BPSR & 0.242 & 0.021 & 0.052 \\
\hline \multicolumn{4}{|l|}{ Axial rotation } \\
\hline UPSR $v s$ BPSR & 0.019 & 0.002 & 0.002 \\
\hline UPSR $v s$ TFPS & 0.005 & $<0.001$ & $<0.001$ \\
\hline TFPS $v s$ BPSR & 0.444 & 0.003 & $\mathbf{0 . 0 3 7}$ \\
\hline
\end{tabular}

Values in boldface are statistically significant $(p<0.05)$.

Abbreviation List

UPSR: unilateral pedicle screw rod; BPSR: bilateral pedicle screw rod; TFPS: transfacet pedicle screw rod; LZ: lax zone; SZ: stiff zone; ROM: range or movement

Measurements using digital handheld calipers showed that the mean distance from the distal (caudal) edge of each L5 facet articulation to the closest edge of respective TFPS washer was $6.8 \pm 2.7 \mathrm{~mm}$ (range: 2.5 to $9.9 \mathrm{~mm}$ ). The TFPS correctly pinned both right and left facet joints in all but only one-side pinned of seven specimens. One of fourteen TFPS penetrated the canal. No standard pedicle screws violated the L5 or S1 pedicle walls.

\section{DISCUSSION}

This study aimed to directly assess empiric biomechanical testing of TFPS and PSR limiting variables of such as difference in size and disc replacement. Bilateral TFPS demonstrated equivalent or better immediate fixation compared to both BPSR and UPSR.

The facet joints are responsible for two of the three points of contact between two adjacent vertebrae and any technique that seeks fusion should thus, fixate the facets in order to decrease mobility at the facets and promote fusion between the opposing bony surfaces according to Wolff's Law (27). To achieve complete fusion, decortication of facets have been described in both posterolateral and posterior lumbar fusion $(28,29)$. The first technique involving facet screws for lumbar 
spine fusion was described by King in 1948 (7), who used 19$25 \mathrm{~mm}$ screws directly across the facet joint. This technique was then modified by Boucher (11), using longer (38-50 mm) screws that also traversed the facets but were angled mediolaterally to enter the pedicle and vertebral body also. These two techniques and the translaminar facet screw (LFS) technique described by Magerl (30), are the three popular approaches to achieve fixation through the facet joint. In contrast, pedicle screw fixation bridges the facet joints from pedicle-to-pedicle thus, indirectly stabilizing the facets.

The L5-S1 segment is associated with high forces due, to the fused sacral segments producing a long level arm and thus, increasing the risk for instrumentation failure especially, with an intact soft-disc. To our knowledge, this is the first empir-ic biomechanical study on the performance of TFPS versus PSR fixation, using equivalent screw dimensions across the L5-S1 motion segment with an intact disc. The only previous biomechanical study in intact disc reported that the TFPS group had slightly better performance in flexion-extension, and slightly significantly worse with LB and AR at the L4-L5 level (8). Transfacet pedicle screw resulted in reduced motion (20\%) when compared to BPS $(24 \%)$ in flexion-extension in the non-ALIF model, but had an increased ROM in LB (37\% vs 22\%) and AR (41\% vs $34 \%)$. The lengths and diameters of the screws were not reported, but the differences from the current study's findings suggest that equivalent sized screw dimensions for TFPS and PSR were not assessed.

We postulate that biomechanically $\mathrm{LB}$ and AR are the worst modes for TFPS compared with PSR fixation, because in TFPS fixation, the screws are more medially positioned and very near the axis of rotation in the coronal plane. As such, there is not as sound a lever arm against lateral bending as pedicle screws have, where the screw heads are placed much farther laterally. Although we found TFPS to allow less LB than bilateral PSR (Fig. 5), the magnitude of the difference compared to the intact specimen was less than during flexion or extension. However, L5-S1 allows markedly less LB than flexion or extension in the non-instrumented condition.

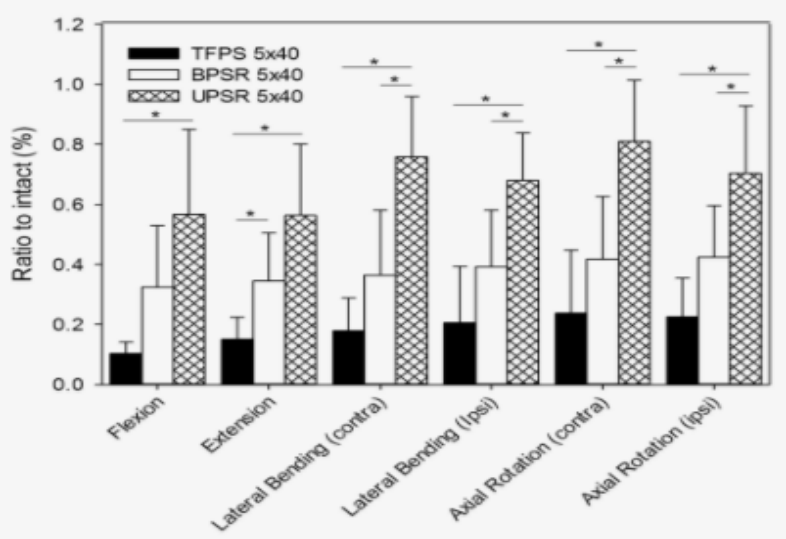

Fig. 5: Comparison of mean normalized unidirectional ROM for 1) Bilateral transfacet pedicle screws (TFPS); 2) Bilateral pedicle screwsrods (BPSR) and 3) Unilateral pedicle screws-rod (UPSR). Error bars show standard devi-ation of the normalized ROM. $* p<0.05$.
A previous biomechanical comparison was made between TFPS $(4.5 \times 40 \mathrm{~mm})$ and PSR $(6.5 \times 40 \mathrm{~mm})$, both instrumented with an interbody cage at L1-L2 and L3-L4 (31). Both techniques achieved significantly decreased ROM compared to the intact spine, but no difference was seen between the two instrumented techniques. In addition, the ROM did not significantly change over time for either technique after 180 000 cycles of fatigue loading. Our results have demonstrated differences between TFPS and PSR stabilization techniques not demonstrated by earlier biomechanical comparison, most likely due, to the disparity in screw diameters used in their TFPS and PSR groups and the study of L5-S1 instead of upper or middle lumbar motion segments. These differences in biomechanical outcome measures may also be due, to the different locations of centre rotation.

Another analysis compared stand-alone anterior lumbar fusion (ALIF) to ALIF + short facet screws (FS), ALIF + translaminar facet screws (LFS) and ALIF+PSR (32); these results demonstrated that there were no biomechanical differences found between the two facet techniques (FS vs LFS) and that there was significantly better flexion/rotation stiffness in PSR techques compared toboth facet fixation techniques. The length/diameter of screws, however, was not described. In a similar study, a comparison of stand-alone ALIF, ALIF+TFPS (4.5 x 26-32 $\mathrm{mm}), \operatorname{ALIF}+\mathrm{LFS}(4.5 \times 38-50 \mathrm{~mm})$ and ALIF+PSR $(6-7 \times$ 40-50 mm) was made (33). Again, the mean ROM and NZ were significantly reduced when posterior screws were added after inserting an interbody cage, but no difference in ROM or NZ was observed between the screw techniques. These results should prompt further quantification of the stabilizing effects of TFPS and PSR when used after an interbody cage, at all lumbar motion segments, and when used with better consistency of screw diameters to determine if the differences, we have demonstrated between these two techniques, persist.

Mahar et al (34), compared the stiffness and the anterior column loads (measured by a load cell inserted in the interbody space simulating a cage) of the TFPS and PSR techniques and found no significant differences between groups. The TFPS and PSR would deliver different compression across the disc space. The TFPS should compress more because of the down-ward screw angle, but this would not be as easy to control as pedicle screws, which allow compression of the implanted screws before locking the screw heads to the interconnecting rods. Similarly, it should be easier to control the final lordosis of the L5-S1 motion segment instrumented with PSR by manipulating the screws implanted in L5 and S1 before locking the heads together. Correct lordosis is especially important at L5-S1 for achieving proper sagittal balance. These findings and considerations again suggest further study comparing the two stabilization methods together with an interbody cage to ascertain if our results persist in those conditions.

Another study reported a biomechanical comparison of LFS, TFPS and PSR as supplementary fixation methods for ALIF (35). These results demonstrated that all techniques produced significant additional stabilization in all loading modes, 
even though TFPS fixation, produced a slightly inferior biomechanical result compared with LFS and PSR. Comparing the three screw techniques, the only statistically significant difference was in LB, comparing PSR to TFPS. This finding is different to our own, in which we have shown better performance with TFPS than PSR in all directions of loading, with significantly less ROM allowed during axial rotation and extension.

We postulate, however, that some of the different results observed in this study when compared with others' work may in fact be due, to the wide washers on the heads of our TFPS screws, or using a wider diameter screw. A wide washer head should help distribute load to a wider area and wider diameter screws have demonstrated significant increases in axial pullout force but no significant increase in transverse bending stiffness (36). The large facets and pedicles at L5-S1 are particularly well suited for large diameter screws with wide washers. Further study is needed to directly compare results with and without washers in a single study to assess the benefit of this feature.

Best et al showed that facet screws had a lower-rate of reoperation compared to pedicle screws (37). Facet screws are less invasive and lower in cost, but may not be appropriate for some patients with severe facet pathology or anatomic abnormality. Therefore, the choice of facet screws or pedicle screws should be carefully considered prior to surgery. The challenges of percutaneous pedicle screw fixation include, L5-S1 screw head proximity (38) and loosening of S1 screws especially in long constructs (39). Neither of these two specific challenges was encountered in this biomechanical analysis.

Limitations of our study are mostly related to the clinical relevance of these data. We have not used standard pedicle screw-rod fixation in our comparison. Rather, the PSR used in this work are both too short and too small in diameter for use in usual lumbosacral pedicle screw fixation in the adult patient. So although we have shown differences in biomechanical performance of the TFPS compared with the PSR, our results cannot be directly compared to a clinical situation. There is some inherent bias introduced in our work because we have used a small diameter and length screws and small rod for the PSR construct, as such we suggest, testing these constructs in more clinically relevant models. The testing of similar sized screws was also performed using intact vertebral discs to reduce the number of variables for testing however, this is not applicable in clinical scenarios.

In this study comparing one size of PSR with the same size TFPS, we report relatively poor results with unilateral PSR compared with good ones using TFPS. This may imply that unilateral TFPS combined with contralateral PSR may, biomechanically, be another suitable option for posterior fixation. Further study is again needed, however, to directly address the feasibility of this proposed surgical construct and to test these constructs in a more clinically relevant model.

\section{CONCLUSION}

The ability of bilateral TFPS to provide the same or better immediate postoperative stability in vitro than the same sized PSR indicates that TFPS fixation at L5-S1 may be a good alternative for posterior fixation at this level. The biomechanical data presented is limited to the use of same sized TFPS and PSR which are smaller than used in clinical setting in lumbar spines with intact discs. Cyclic testing prior to further biomechanical evaluation of TFPS or PSR, and clinical studies are needed to test and clarify the clinical relevance of these biomechanical findings and recommendations.

\section{ACKNOWLEDGMENT}

The authors gratefully acknowledge the assistance of Dr V Cumming, Dr E Hothem, LES Society, in researching, drafting and editing the manuscript.

\section{AUTHORS' NOTE}

Dr KR Chin is a shareholder in and receives other benefits from SpineFrontier Inc. WDY, and CB are consultants for SpineFrontier Inc.; and NRC and PMR have received travel benefits from SpineFrontier Inc. None of the other authors (MTR, AGUN, DM, and FJRP) have any potential conflicts of interest to declare for this work. Funding for this work was received from the Society of Facet Surgical Techniques and Technologies Inc (SOFAST). We have not received any funding for this work in any form from the National Institutes of Health, Wellcome Trust, or Howard Hughes Medical Institute.

\section{REFERENCES}

1. Zindrick MR. The role of transpedicular fixation systems for stabilization of the lumbar spine. Orthop Clin North Am 1991; 22: 333-44.

2. Highsmith JM, Tumialan LM, Rodts GE, Jr. Flexible rods and the case for dynamic stabilization. Neurosurg Focus 2007; 22: E11.

3. Bono CM, Kadaba M, Vaccaro AR. Posterior pedicle fixation-based dynamic stabilization devices for the treatment of degenerative diseases of the lumbar spine. J Spinal Disord Tech 2009; 22: 376-83.

4. Vaccaro AR, Garfin SR. Internal fixation (pedicle screw fixation) for fusions of the lumbar spine. Spine 1995; 20 (24 Suppl): 157S-65S.

5. El Masry MA, McAllen CJ, Weatherley CR. Lumbosacral fusion using the Boucher technique in combination with a posterolateral bone graft. Eur Spine J 2003; 12: 408-12.

6. Hida S, Naito M, Arimizu J, Morishita Y, Nakamura A. The transverse placement laminoplasty using titanium miniplates for the reconstruction of the laminae in thoracic and lumbar lesion. Eur Spine J 2006; 15: 1292-7.

7. King D. Internal fixation for lumbosacral fusion. J Bone Joint Surg Am 1948; 30A: 560-5.

8. Agarwala A, Bucklen B, Muzumdar A, Moldavsky M, Khalil S. Do facet screws provide the required stability in lumbar fixation? A biomechanical comparison of the Boucher technique and pedicular fixation in primary and circumferential fusions. Clin Biomech 2012; 27: 64-70.

9. Burton D, McIff T, Fox T, Lark R, Asher MA, Glattes RC. Biomechanical analysis of posterior fixation techniques in a 360 degrees arthrodesis model. Spine 2005; 30: 2765-71.

10. Harris BM, Hilibrand AS, Savas PE, Pellegrino A, Vaccaro AR, Siegler $\mathrm{S}$ et al. Transforaminal lumbar interbody fusion: the effect of various instrumentation techniques on the flexibility of the lumbar spine. Spine 2004; 29: E65-70.

11. Boucher HH. A method of spinal fusion. J Bone Joint Surg Br 1959; 41-B: 248-59. 
12. Panjabi MM, Yamamoto I, Oxland TR, Crisco JJ, Freedman D. Biomechanical stability of five pedicle screw fixation systems in a human lumbar spine instability model. Clin Biomech 1991; 6: 197-205.

13. Kretzer RM, Molina C, Hu N, Umekoji H, Baaj AA, Serhan H et al. A comparative biomechanical analysis of stand-alone versus facet screw and pedicle screw augmented lateral interbody arthrodesis: an in vitro human cadaveric model. J Spinal Disord Tech 2013. Epub 2013/02/06. doi: 10.1097/BSD.0b013e3182868ef9. PubMed PMID: 23381181.

14. Chin KR, Newcomb AG, Reis MT, Reyes PM, Hickam GA, Gabriel J et al. Biomechanics of posterior instrumentation in L1-L3 lateral interbody fusion: Pedicle screw rod construct vs. transfacet pedicle screws. Clin Biomech 2016; 31: 59-64.

15. Rhee JW, Petteys RJ, Anaizi AN, Sandhu FA, Voyadzis JM. Prospective evaluation of 1-year outcomes in single-level percutaneous lumbar transfacet screw fixation in the lateral decubitus position following lateral transpsoas interbody fusion. Eur Spine J 2015; 24: 2546-54.

16. Chin KR, Seale J, Cumming V. Mini-open or percutaneous bilateral lumbar transfacet pedicle screw fixation: a technical note. J Spinal Disord Tech 2015; 28: 61-5.

17. Vaccaro AR, Garfin SR. Pedicle-Screw Fixation in the Lumbar Spine. J Am Acad Orthop Surg 1995; 3: 263-74.

18. Arman C, Naderi S, Kiray A, Aksu FT, Yilmaz HS, Tetik S et al. The human sacrum and safe approaches for screw placement. J Clin Neurosci 2009; 16: 1046-9.

19. Crawford NR, Dickman CA. Construction of local vertebral coordinate systems using a digitizing probe. Technical note. Spine 1997; 22: 559-63.

20. Panjabi MM. Biomechanical evaluation of spinal fixation devices: I. A conceptual framework. Spine 1988; 13: 1129-34.

21. Yucesoy K, Yuksel KZ, Baek S, Sonntag VK, Crawford NR. Biomechanics of unilateral compared with bilateral lumbar pedicle screw fixation for stabilization of unilateral vertebral disease. J Neurosurg Spine 2008; 8: 44-51. Epub 2008/01/05. doi: 10.3171/spi-08/01/044. PubMed PMID: 18173346.

22. Karahalios DG, Kaibara T, Porter RW, Kakarla UK, Reyes PM, Baaj AA et al. Biomechanics of a lumbar interspinous anchor with anterior lumbar interbody fusion. J Neurosurg Spine 2010; 12: 372-80.

23. Perez-Orribo L, Kalb S, Reyes PM, Chang SW, Crawford NR. Biomechanics of lumbar cortical screw-rod fixation versus pedicle screw-rod fixation with and without interbody support. Spine 2013; 38: 635-41.

24. Crawford NR, Peles JD, Dickman CA. The spinal lax zone and neutral zone: measurement techniques and parameter comparisons. J Dis Spinal Disord 1998; 11: 416-29.

25. Crawford NR, Yamaguchi GT, Dickman CA. A new technique for determining 3-D joint angles: the tilt/twist method. Clin Biomech 1999; 14: 153-65.
26. Crawford NR, Peles JD, Dickman CA. The spinal lax zone and neutral zone: measurement techniques and parameter comparisons. J Spinal Disord 1998; 11: 416-29.

27. Stedman TL. Stedman's Medical Dictionary for the Health Professions And Nursing: Lippincott Williams \& Wilkins; 2007.

28. Slappey G, Toribatake Y, Ganey TM, Ogden JA, Hutton WC. Guidelines to decortication in posterolateral spine fusion. J Spinal Disord 1998; 11: 102-9. Epub

29. Agazzi S, Reverdin A, May D. Posterior lumbar interbody fusion with cages: an independent review of 71 cases. J Neurosurg. 1999; 91 (Suppl 2): $186-92$.

30. Magerl FP. Stabilization of the lower thoracic and lumbar spine with external skeletal fixation. Clin Orthop Relat Res 1984: 125-41. Ferrara

31. LA, Secor JL, Jin BH, Wakefield A, Inceoglu S, Benzel EC. A biomechanical comparison of facet screw fixation and pedicle screw fixation: effects of short-term and long-term repetitive cycling. Spine 2003; 28: $1226-34$

32. Kandziora F, Schleicher P, Scholz M, Pflugmacher R, Eindorf T, Haas NP et al. Biomechanical testing of the lumbar facet interference screw. Spine (Phila Pa 1976). 2005; 30: E34-9.

33. Beaubien BP, Mehbod AA, Kallemeier PM, Lew WD, Buttermann GR, Transfeldt EE et al. Posterior augmentation of an anterior lumbar interbody fusion: minimally invasive fixation versus pedicle screws in vitro. Spine 2004; 29: E406-12.

34. Mahar A, Kim C, Oka R, Odell T, Perry A, Mirkovic S et al. Biomechanical comparison of a novel percutaneous transfacet device and a traditional posterior system for single level fusion. J Spinal Disord Tech 2006; 19: 591-4.

35. Kim SM, Lim TJ, Paterno J, Kim DH. A biomechanical comparison of supplementary posterior translaminar facet and transfacetopedicular screw fixation after anterior lumbar interbody fusion. J Neurosurg Spine 2004; 1: 101-7.

36. Wittenberg RH, Lee KS, Shea M, White AA $3^{\text {rd }}$, Hayes WC. Effect of screw diameter, insertion technique, and bone cement augmentation of pedicular screw fixation strength. Clin Orthop Relat Res 1993: 278-87.

37. Best NM, Sasso RC. Efficacy of translaminar facet screw fixation in circumferential interbody fusions as compared to pedicle screw fixation. J Spinal Disord Tech 2006; 19: 98-103.

38. Mobbs RJ, Sivabalan P, Li J. Technique, challenges and indications for percutaneous pedicle screw fixation. J Clin Neurosci 2011; 18: 741-9.

39. Fleischer GD, Kim YJ, Ferrara LA, Freeman AL, Boachie-Adjei O. Biomechanical analysis of sacral screw strain and range of motion in long posterior spinal fixation constructs: effects of lumbosacral fixation strategies in reducing sacral screw strains. Spine 2012; 37: E163-9. 